\title{
GRUPOS REFLEXIVOS COM HOMENS PARA PREVENÇÃO DA VIOLÊNCIA CONJUGAL: COMO ORGANIZÁ-LOS
}

\author{
REFLECTIVE GROUPS WITH MEN TO PREVENT \\ CONJUGAL VIOLENCE: HOW TO ORGANIZE THEM
}

\section{GRUPOS REFLEXIVOS CON HOMBRES PARA LA PREVENCIÓN DE LA VIOLENCIA CONYUGAL: CÓMO ORGANIZARLOS}

\author{
Fernanda Matheus Estrela ${ }^{1}$ \\ Nadirlene Pereira Gomes ${ }^{2}$ \\ Andrey Ferreira da Silva ${ }^{3}$ \\ Júlia Renata Fernandes de Magalhães ${ }^{4}$ \\ Anderson Reis de Souza \\ Álvaro Pereira ${ }^{6}$
}

\begin{abstract}
Como citar este artigo: Estrela FM, Gomes NP, Silva AF, Magalhães JRF, Souza AR, Pereira A. Grupos reflexivos com homens para prevenção da violência conjugal: como organizá-los. Rev baiana enferm. 2019;33:e32999.

Objetivo: descrever a construção de um grupo reflexivo com homens com vistas à prevenção e ao enfrentamento da violência conjugal. Método: estudo descritivo, tendo como referencial a Perspectiva Crítico-Libertadora de Paulo Freire. O público-alvo foram 44 homens que respondiam processo em Salvador, Bahia. Resultados: o passo a passo da construção do grupo reflexivo teve os seguintes requisitos: definição do projeto didático-metodológico; obtenção de recursos humanos, materiais e financeiros; escolha do espaço para desenvolvimento do grupo reflexivo e captação do público-alvo. Conclusão: a implementação desses espaços educativos apresenta viabilidade financeira e operacional, considerando seu potencial de redução de casos de violência conjugal, podendo ser replicado por profissionais de diferentes áreas de atuação, em diferentes cenários e com homens de todos os níveis socioculturais.
\end{abstract}

Descritores: Violência contra a Mulher. Violência de Gênero. Homens. Metodologia. Prevenção.

Objective: to describe material the construction of a reflective group for men intending to prevent and cope conjugal violence. Method: descriptive study, whose reference was the Critical-Emancipatory Perspective of Paulo Freire. The participants were 44 prosecuted men in Salvador, Babia. Results: the step by step to construct the reflective group had the following requirements: definition of the didactic-methodological project; buman, and financial resources; location for the development of the reflective group; and the gathering of the target population. Conclusion: the implementation of these educational spaces is financially and operationally feasible, considering their potential

\footnotetext{
Enfermeira. Doutora em Enfermagem. Professora da Universidade Estadual de Feira de Santana. Feira de Santana, Bahia, Brasil. nanmatheus@yahoo.com.br. https:// orcid.org/0000-000 I-750|-6187

Enfermeira. Doutora em Enfermagem. Professora da Universidade Federal da Bahia. Salvador, Bahia, Brasil. https://orcid.org/0000-0002-6043-3997

Enfermeiro. Doutor em Enfermagem. Professor Substituto da Universidade Federal de Alagoas. Maceió. Alagoas, Brasil. https://orcid.org/0000-0002-1038-7443

Enfermeira. Mestre em Enfermagem Universidade Federal da Bahia. Salvador, Bahia, Brasil. https://orcid.org/0000-0003-063 I-2374

Enfermeiro. Mestre em Enfermagem. Professor da Universidade Federal da Bahia. Salvador, Bahia, Brasil. https://orcid.org/0000-000 I-8534- 960

Enfermeiro. Doutor em Filosofia da Enfermagem. Professor da Universidade Federal da Bahia. Salvador, Bahia, Brasil. https://orcid.org/0000-0003-161 5-5528
} 
for reducing cases of conjugal violence, which can be replicated by professionals from different fields of activity, in different scenarios and with men from all socio-cultural levels.

Descriptors: Violence against Women. Gender-Based Violence. Men. Methodology. Prevention.

Objetivo: describir la construcción de un grupo reflexivo para hombres con miras a prevenir y enfrentar la violencia conyugal. Método: estudio descriptivo, tomando como referencia la Perspectiva Crítico-Emancipadora de Paulo Freire. El público fueron 44 hombres respondiendo proceso judicial en Salvador, Babia. Resultados: el paso a paso en la construcción de los reflejos en el grupo tuvo los siguientes requisitos: definición del diseño didáctico-metodológico; la obtención de recursos humanos, materiales y financieros; la elección del espacio para el desarrollo de grupo reflexivo y captura del público objetivo. Conclusión: la implementación de estos espacios educativos es financiera y operacionalmente factible, considerando su potencial para reducir los casos de violencia conyugal, que pueden ser reproducidos por profesionales de diferentes campos de actividad, en diferentes escenarios y con hombres de todos los niveles socioculturales.

Descriptores: Violencia contra la Mujer. Violencia de Género. Hombres. Metodología. Prevención.

\section{Introdução}

A violência conjugal é um problema de saúde pública, responsável por altas taxas de morbimortalidade da população feminina em todo o mundo. Diante dos impactos físicos, mentais e sociais desse fenômeno, percebeu-se a necessidade de criação de mecanismos de enfrentamento, dentre eles a implementação da Lei Maria da Penha. Esta, para além de aumentar o rigor das punições, reconhece a importância de ações educativas direcionadas aos agressores, embora não aponte o caminho para sua implementação.

Ressalta-se que esses mecanismos de enfrentamento e prevenção da violência, pensados e denominados de grupos reflexivos (GR), foram considerados como uma tecnologia social. Esta é definida como uma metodologia que pode ser reaplicada e remete para uma proposta inovadora de desenvolvimento, considerando uma abordagem construtivista na participação coletiva do processo de organização, desenvolvimento e implementação. Está baseada na disseminação de soluções para problemas voltados às demandas de saúde, aliando o saber popular e o conhecimento técnico-científico.

Pesquisa mundial aponta que, em 2016, cerca de 87.300 mulheres foram mortas, a maioria delas assassinadas por seus cônjuges ${ }^{(1)}$. Aquelas que sobrevivem às agressões geralmente apresentam-se adoecidas física e mentalmente, podendo manifestar tanto lesões corporais como hematomas, fraturas e queimaduras, além de comportamento depressivo, a exemplo de medo, baixa autoestima e tristeza ${ }^{(2-3)}$.

Mesmo com todos os impactos da violência para a saúde das mulheres, foi somente a partir da década de 70, com as denúncias e reivindicações do Movimento Feminista, que essa problemática passou a ganhar visibilidade. Para o enfrentamento dessa realidade, foram criados diversos equipamentos, a exemplo da primeira Delegacia Especializada no Atendimento da Mulher (DEAM), implementada em $1985^{(4)}$. No âmbito jurídico, em 1995, foi criada a Lei dos Juizados Especiais, embora tal sistema não tenha sido eficaz para a proteção das mulheres, pois abrangia apenas infrações penais de menor potencial ofensivo, além de possibilitar a conversão da pena em cestas básicas e a suspensão condicional do processo. Dessa forma, o que ocorria é que os homens sentiam-se impunes, visto que, em raros casos, seriam presos devido à violência contra a mulher ${ }^{(4)}$.

Diante das mencionadas fragilidades desse sistema, a justiça reconheceu a urgência de uma lei mais rigorosa. Em meio a esse contexto, em 2006, foi sancionada a Lei n. 11.340, que criava mecanismos para coibir, prevenir e erradicar todas as formas de abuso contra a mulher. Dentre os seus avanços, destacam-se: medidas protetivas de urgência; proibição de penas pecuniárias 
e da entrega da intimação ao agressor pela mulher; possibilidade da prisão, tanto em flagrante quanto preventiva; bem como necessidade de notificar à mulher quanto aos atos processuais, especialmente quanto ao ingresso e à saída do agressor da prisão ${ }^{(5)}$.

Além de mais severa, a lei prevê ainda a criação de centros de educação e reabilitação para os autores de violência conjugal, os quais devem comparecer de forma obrigatória, mediante determinação judicial. Entretanto, a lei não deixa clara a periodicidade e quantidade de encontros ${ }^{(5)}$. Nesse sentido, observa-se uma construção social pautada em questões de gênero que direciona os homens a tornarem-se agressores e as mulheres a submeterem-se à violência ${ }^{(6-7)}$, sendo necessários espaços educativos para reflexão e sensibilização masculina, com o propósito de não naturalizar o abuso e possibilitar a mudança de comportamento.

Vale salientar que, apesar de a legislação e os diversos estudos sinalizarem a importância desses espaços educativos, existem poucas evidências científicas que expliquem qual a metodologia utilizada para implementação de grupos com a finalidade educativa. Em busca realizada sobre a temática na base de dados do periódico Capes, com recorte temporal de 10 anos (2008-2018), por ter sido o marco da criação da Política Nacional de Atenção Integral à Saúde do Homem, foram encontrados quatro estudos, entretanto nenhum deles elucidava a metodologia utilizada $^{(4,6-8)}$. A escassez de informações sobre o tema reflete a reduzida utilização da estratégia Grupos Reflexivos com homens autores de violência conjugal no país.

Dentre as 26 unidades federativas, apenas seis estados (Santa Catarina, Rio de Janeiro, Minas Gerais, Distrito Federal e Bahia) realizam GR com homens autores de violência, porém não esclarecem a metodologia utilizada e a maneira de organização de tais grupos, conforme estudo realizado no Sul do Brasil $^{(7)}$. Outros estudos no Brasil e Estados Unidos, que abordam grupos com homens autores de violência, não relatam o passo a passo de como são realizados, quais temáticas, qual a forma de realizar a articulação esperada para a sua realização ${ }^{(2,6)}$. Nos estados brasileiros onde já foram realizados GR para homens autores de violência, partiu-se de resultados de experiências de ações educativas com mulheres, que mostraram a contribuição das ações informativas e educativas para o empoderamento feminino ${ }^{(2,9)}$.

No intuito de preencher essa lacuna na cidade de Salvador, Bahia, e compartilhar experiências que possam subsidiar a formulação e implementação de GR e, com isso, a operacionalização da lei, este estudo tem como objetivo descrever a construção de um grupo reflexivo com homens com vistas à prevenção e ao enfrentamento da violência conjugal.

\section{Método}

Estudo exploratório, descritivo, oriundo da tese intitulada "Tecnologia Social para Homens com Vistas à Prevenção da Violência Conjugal”, financiada pela Fundação de Amparo à Pesquisa do Estado da Bahia e aprovada pelo Parecer n. 877.905 do Comitê de Ética em Pesquisa da Universidade Federal da Bahia. Trata-se de recorte da pesquisa-ação, utilizada enquanto método de criação de tecnologia social e que tem no campo da saúde ênfase na participação popular, principalmente na saúde coletiva. A construção deste artigo foi pautada na segunda das cinco fases da pesquisa-ação. São elas: diagnóstico, planejamento das ações, execução das ações, avaliação e análise dos dados.

O estudo teve como cenários a $1^{\underline{a}}$ e a $2^{\underline{a}}$ Varas de Justiça pela Paz em Casa, localizadas no município de Salvador, Bahia, Brasil. Os participantes foram 44 homens envolvidos em processo jurídico por violência conjugal junto às referidas Varas. Os critérios de inclusão foram: terem participado de $75 \%$ dos encontros (no mínimo 6 encontros) e estarem aptos emocionalmente para participar do estudo. Ressalta-se que os homens receberam da juíza uma intimação judicial para participação nos GR, de modo a fazer cumprir a Lei n. 11.340/2006, que preconiza a participação de homens em atividades reflexivas de educação em gênero. Entretanto, mesmo sendo 
obrigatório participar do GR, foi esclarecido que a participação na pesquisa era livre e voluntária. Foi-lhes assegurado o princípio da autonomia, conforme Resolução CNS/MS n. 466/2012, e solicitou-se que assinassem o Termo de Consentimento Livre e Esclarecido (TCLE).

Os homens eram avaliados emocionalmente pela psicóloga que integrava o Grupo Vid@ juntamente com as pesquisadoras. Em cada ciclo de oito encontros, a juíza enviava uma lista com aproximadamente 15 nomes, totalizando cerca de 60 homens nos cinco ciclos realizados. A partir desse momento, já com data definida, o Grupo Vid@ fazia um contato telefônico para reforçar as datas, horário e local dos encontros. Ressalta-se que 16 homens não participaram de 75\% dos encontros e, por esta razão, foram excluídos. Os GR foram realizados com 44 homens, divididos em cinco ciclos: o primeiro, segundo e quinto ciclos compuseram-se de nove homens em cada ciclo; o terceiro, por 14 homens em cada; e o quarto, por três homens.

O primeiro GR foi realizado no final de 2016, configurando-se como estudo piloto, que ainda necessitava de ajustes para ser implementado nos próximos grupos. Dessa forma, atentou-se para o levantamento das questões que necessitavam de mudanças, de modo a melhor reorganizar novos GR nos anos de 2017 e 2018, com quatro ciclos subsequentes. Os grupos foram avaliados no oitavo encontro (final de cada Grupo Reflexivo), visando verificar se as expectativas dos participantes em relação à sessão foram alcançadas; se o conteúdo, organização, didática e recursos materiais foram adequados, além de avaliar preliminarmente a eficiência dos GR.

\section{Resultados}

Nesta seção, serão apresentados os requisitos para o desenvolvimento de grupos reflexivos para homens em processo criminal por violência conjugal. Para a elaboração do GR, foi definido o projeto didático-metodológico, obtidos os recursos humanos, materiais e financeiros, selecionado o espaço para desenvolvimento do GR e criada estratégia para a captação do público-alvo.

\section{Definição do projeto didático-metodológico}

O primeiro passo para o desenvolvimento de GR consistiu em definir qual seria o projeto para a condução das ações educativas, com o propósito de prevenção da violência conjugal. Para tanto, foi necessária pesquisa em base de dados indexadas, para captar estratégias que pudessem ser aplicadas para o delineamento dos grupos e da dimensão dos impactos de cada atividade para a reflexão masculina, percepção e responsabilização de suas condutas e consequentemente mudanças de comportamento para o desenvolvimento de relações conjugais e familiares respeitosas.

A escolha das temáticas pautou-se na Perspectiva Crítico-Libertadora de Paulo Freire ${ }^{(10)}$ e no princípio epistemológico, o qual valoriza o conhecimento trazido pelos sujeitos e o diálogo, busca-se a superação de situações-limites e mudança de visão de mundo não pela substituição de saberes, mas por um diálogo apoiado nos saberes trazidos pelos indivíduos. Pretendia-se, com a criação e implementação dos GR, que os homens pudessem refletir sobre o cotidiano, visando a criação e a recriação de sua práxis com base nos conflitos vivenciados ${ }^{(11)}$. Nesse sentido, a proposta apoiou-se no argumento de Paulo Freire, ao defender que o empoderamento pode dar-se por meio da educação dos sujeitos e que esta deve contribuir para uma sociedade mais livre e justa e para a superação das diversas formas de exploração e dominação vigentes ${ }^{(10)}$.

As temáticas escolhidas para operacionalizar o GR foram organizadas em oito encontros que tinham por objetivo provocar reflexões sobre família, gênero, masculinidade, violência e resolução pacífica de conflitos, conforme estudos brasileiros e internacionais sobre o tema. Os encontros foram programados para as quintas-feiras, dia escolhido aleatoriamente, de 17 h 30 min às 19 h $30 \mathrm{~min}$, com as temáticas e objetivos organizados após diversas modificações propostas nos 
grupos, pautados numa relação dialógica. A cada ciclo realizado, os homens poderiam propor novos temas a serem abordados, considerando o contexto social, cultural e econômico.

Para o primeiro encontro, foi programada a apresentação do GR, com o objetivo de socializar os integrantes com a equipe de trabalho; o $2^{\circ}$ encontro, com a temática influência da família na formação do "eu", teve o intuito de incitar o valor da instituição família e alertar para sua influência na reprodução de comportamentos; o $3^{\text {o }}$ encontro, sobre a construção social da desigualdade de gênero, propôs-se a esclarecer quais papéis e funções atribuídos a homens e mulheres foram construídos e reproduzidos historicamente; o $4^{\underline{0}}$ encontro, com o intuito de alertar sobre as consequências do modelo hegemônico de "ser homem" em face da vulnerabilidade masculina das doenças/agravos e da necessidade de novos modelos de masculinidades ancorados no respeito e na afetividade, teve como foco a temática masculinidades e a formação do "novo homem"; o $5^{\circ}$ encontro visou cooperar com o entendimento dos agravos de saúde a que a população masculina está vulnerável, pelo fato de "ser homem" e incentivar o autocuidado com a saúde e as relações conjugais saudáveis. Já o 6$^{0}$ encontro possibilitou o reconhecimento, por parte dos homens, das condutas desrespeitosas/violentas e a responsabilização criminal; o 7º, abordou resoluções pacíficas para incitar a percepção masculina acerca dos elementos precipitadores/intensificadores da violência conjugal e estratégias pacíficas para resolução de conflitos; no $8^{\circ}$ e último encontro, foi realizada a avaliação do impacto do GR para a transformação masculina, sobretudo nas relações familiares e conjugais.

Utilizou-se, como estratégias, das metodologias ativas, com o recurso da problematização, uso de vídeos, músicas, reportagens atuais que fizessem os homens refletirem sobre as temáticas abordadas. O GR visou também incluir a participação de doutorandos do grupo VID@, apoio dos orientadores e de bolsistas da graduação, denominados de equipe de trabalho (ET). Foram realizadas também atividades de dispersão, com temas do encontro seguinte, de modo que os homens pudessem refletir sobre o cotidiano, visando a criação e recriação de sua práxis com base nos conflitos vivenciados, conforme propõe Paulo Freire ${ }^{(10)}$.

Quanto ao recorte temporal, cada encontro durou em média $2 \mathrm{~h}$ (totalizando 16 h), sendo reservados $30 \mathrm{~min}$ para lanche e socialização dos participantes. Nesses momentos de descontração, os homens poderiam sentir-se à vontade para partilhar suas vivências e perspectivas, tanto em relação ao grupo quanto aos seus relacionamentos familiares e conjugais. Dos oito encontros, sete ocorreram semanalmente e o último com o espaço de um mês, de modo que os homens pudessem refletir as transformações que resultaram das vivências no GR.

\section{Obtenção de recursos bumanos, materiais e financeiros}

O GR, nesta experiência, foi conduzido por uma equipe de trabalho do Grupo Vid@ integrada por 4 docentes e 15 discentes da graduação e pós-graduação que se dedicavam a atividades de ensino, pesquisa e extensão acerca da temática violência, com a finalidade da prevenção e do enfrentamento do fenômeno. Os recursos humanos que operacionalizam os GR são constituídos por integrantes da área de direito, psicologia e serviço social, embora predominem as(os) profissionais enfermeiras(os). Houve cerca de 6 encontros com a ET previamente à realização dos GR, para planejar as dinâmicas que seriam realizadas.

Quanto aos recursos materiais, necessitava-se de: espaço físico que garantisse a acomodação dos participantes com o mínimo de interrupções externas; equipamentos audiovisuais para projeção, sonorização e gravação; materiais educativos e de consumo (cartucho, papel ofício e metro, entre outros) para a condução do projeto didático-metodológico. Importante a elaboração de um check-list para cada atividade, a ser aplicado pelos responsáveis: recepção dos participantes, com assinatura de lista de frequência individual, a ser entregue à Vara no 
final do GR; entrega de crachás e atestado de comparecimento; montagem dos equipamentos e condução da ação educativa; registro de falas e imagens divulgadas por meio de codinomes; transcrição e validação das falas; aquisição e organização de lanches; entrega de auxílio financeiro para custeio do transporte.

Para o desenvolvimento do GR, urge apoio financeiro para o custeio de todas as atividades inerentes ao grupo reflexivo. Especificamente sobre o suporte técnico, o financiamento é imprescindível para a contratação de profissionais de todas as categorias.

\section{Escolba do espaço para desenvolvimento do GR}

Para o desenvolvimento das atividades, necessitou-se de um espaço que estivesse localizado preferentemente em local de fácil acesso. O escolhido foi uma escola pública situada nas proximidades da Vara, localizada em um bairro central da cidade, permitindo a mobilidade dos participantes por via de transporte público. Os encontros ocorriam às quintas-feiras, das 17 h $30 \mathrm{~min}$ às $19 \mathrm{~h} 30 \mathrm{~min}$. e os participantes eram acolhidos por algum membro do ET, geralmente um dos doutorandos que conduziam os encontros.

\section{Captação do público-alvo}

Para a realização do GR, foram necessárias estratégias de captação de homens, público-alvo, para o direcionamento das ações com o propósito da prevenção da violência conjugal. O critério de escolha desses homens, adotado neste estudo, era estar respondendo a processo criminal por violência conjugal, o que demandou articulações junto às Varas de Justiça pela Paz em Casa. Entretanto, o método proposto adequava-se a qualquer que fosse o espaço em que os homens encontravam-se inseridos - comunidades, Estratégia de Saúde da Família (ESF), trabalhadores motoristas, entre outros.

Poderiam ser realizadas as seguintes estratégias para captar homens para participarem nos GR: convite pelas psicólogas e assistentes sociais que integravam a vara ou pelos membros do Vid@ em salas de espera, na qual os homens aguardavam suas audiências ou intimação judicial. Após esse primeiro contato, eram anotados os telefones, para realizar uma ligação na semana dos encontros, de modo a relembrar a data, local e horário. Uma linha telefônica foi destinada ao GR, e essas ligações foram realizadas por um dos integrantes do ET do sexo masculino, pois acreditava-se que favoreceria o diálogo, o vínculo e consequentemente a adesão às ações educativas. Nessa ligação, explicava-se previamente sobre a pesquisa e a garantia de sigilo e anonimato.

\section{Discussão}

Embora existam iniciativas de desenvolvimento de GR pelo mundo, as metodologias aplicadas são pouco divulgadas. Como exemplo, cita-se a Pesquisa e Intervenção no contexto brasileiro sobre violência, realizada em 2017, que se distanciou dos programas de intervenção nacional e internacionalmente disseminados, que focam nas mulheres ${ }^{(8-9)}$. No cenário internacional, pesquisa realizada nos EUA revela que, em países de baixa e média renda, percebeu-se o uso de grupos femininos e masculinos com foco em intervenções comunitárias entre os casais de modo a prevenir a violência ${ }^{(11)}$. Tal conjuntura acaba por dificultar a reprodução das ações com os homens com foco na prevenção da violência. O número de encontros considerou o contexto socioeconômico nacional e internacional dos homens cuja situação laboral tendia a ficar comprometida com o processo criminal e/ou prisão preventiva ${ }^{(6,8)}$.

Dentre essas ações, destaca-se espaços para que homens e mulheres reflitam acerca da construção social, que determina a naturalização da desigualdade de gênero e a construção da violência conjugal, agravo que impacta negativamente na qualidade de vida, inclusive dos próprios autores da agressão. A este respeito, pesquisa sobre violência realizada no Brasil e nos Estados Unidos da América revelou que os homens compreendem como naturais as atitudes 
violentas nas relações conjugais, não as percebendo enquanto condutas que geram adoecimento de toda a família ${ }^{(6,12)}$.

Essa naturalização da violência também pode ser entendida sob a ótica de Paulo Freire, o qual afirma que a neutralidade seria a maneira mais cômoda, isto é, naturalizar a violência pode ser mais cômodo do que enfrentá-la. Desse modo, para a superação da realidade, o entendimento e reconhecimento do fenômeno é fundamental para a transformação da sociedade ${ }^{(10)}$.

Embora as pesquisas realizadas não tenham alcançado um consenso quanto à duração e ao intervalo entre os encontros das intervenções envolvendo homens com fins de prevenção da violência $^{(8-9)}$, acredita-se que o tempo definido na experiência ora relatada seja essencial, para que a experiência do vivido no GR possa reverberar na vida dos participantes, e estes avaliem o quanto estão dispostos e disponíveis para mudanças, sobretudo na forma com que se relacionam com os familiares, em especial com a(o)s parceira(o)s.

Dessa forma, entende-se que esse modelo de projeto didático-metodológico de baixo custo e facilmente replicável pode ser implementado em diversos cenários, por diferentes categorias profissionais. Esse tipo de proposta é viável porque pode estar presente nos espaços relacionais e materializa-se nas atitudes do sujeito, favorecendo o acolhimento e a integralidade no âmbito da saúde, em especial na atenção básica ${ }^{(9)}$. No cenário nacional, metodologias similares são conduzidas essencialmente por psicólogos, terapeutas ocupacionais, sociólogos e profissionais das ciências sociais, desde que previamente treinados, utilizando perspectivas psicoeducativas, de gênero, masculinidades, direitos humanos, dentre outras ${ }^{(13)}$.

No que se refere às temáticas escolhidas, em diversos locais do mundo, existem alguns programas que incorporam as teorias de masculinidades e gênero em suas intervenções e visam transformar as normas nocivas da masculinidade que promovem a violência, incentivando reflexões sobre o papel masculino na sociedade. Essas intervenções trabalham com homens para refletir as relações maritais e desafiar as normas masculinas nocivas prevalecentes ${ }^{(14)}$. Programas ingleses, como o Projeto $\mathrm{H}$ e o Programa Homens como parceiros da Saúde, mostraram que as intervenções pautadas em gênero e masculinidades podem ser eficazes para o trabalho em grupos com homens e podem reduzir a perpetração da violência ${ }^{(15-16)}$.

Cabe ressaltar o papel fundamental dos profissionais que atuam nos serviços de saúde, em especial a enfermagem, para identificar vulnerabilidades e/ou agravos, como a violência conjugal e seu contexto familiar e social, com vistas à implementação de ações de promoção da saúde, a exemplo de salas de espera com temáticas voltadas para a prevenção e o enfrentamento da violência ${ }^{(2)}$.

Os GR desenvolvidos pelo Grupo Vid@ distinguem-se do modelo implementado nas atividades da área da Segurança Pública, a exemplo das delegacias da mulher e juizados de violência doméstica e familiar ${ }^{(9)}$, visto que se pautam em temáticas como família, gênero, masculinidades, cuidado com a saúde, resolução de problemas de forma pacífica.

No que tange ao espaço físico para a realização dos GR, foi escolhido um dia diferente do que geralmente ocorre o GR de mulheres, para não haver encontro entre esses, evitando situações desagradáveis entre ambos, a exemplo do descumprimento da medida protetiva de urgência ${ }^{(5)}$.

A parceria com as Varas de Justiça pela Paz em Casa, em especial com o serviço psicossocial, possibilitou a aproximação da equipe de trabalho do Vid@ com esse cenário do jurídico, a fim de tornar familiar a dinâmica dos processos, além de favorecer o acesso a esses, tanto para o conhecimento da situação relatada pela denunciante como para esclarecer questionamentos apresentados pelos homens durante o GR.

Estudo realizado em Salvador, Bahia, sobre violência conjugal, evidencia a importância da articulação intersetorial para o desenvolvimento de estratégias que visem o enfrentamento do fenômeno $^{(2)}$. Na experiência ora relatada, essa 
articulação favoreceu o contato com homens que aguardavam uma audiência, momento em que se implementou a estratégia denominada "sala de espera", e fazia-se o convite para integrar o grupo. O convite também era feito pela assistente social e pela psicóloga, durante o atendimento psicossocial.

Apesar de tais estratégias para captação do público masculino, a adesão limitada direcionou a decisão da juíza na expedição de intimação judicial, fazendo, assim, cumprir a Lei n. 11.340, que preconiza a participação de homens em atividades reflexivas de educação em gênero ${ }^{(5)}$. Importante referir que, se por um lado tem-se clareza quanto à importância da participação voluntária dos homens no GR, por outro, entende-se que, ao estarem inseridos em processo jurídico-criminal e diante da naturalização da desigualdade de gênero que impede o reconhecimento de suas ações enquanto criminosas, as medidas judiciais tornam-se imperativas. A necessidade desta determinação é confirmada por pesquisa que defende não existir interesse espontâneo por parte dos homens de mudar nem de se responsabilizar pelos seus atos e que, mesmo quando envolvidos em ações educativas, resistem aos esforços dos facilitadores para que se expressem, não aderindo às intervenções ${ }^{(9,17)}$.

Embora se limite por não delinear a estratégia didático-metodológica dos encontros, que não é foco deste artigo, entende-se que a divulgação do caminho para a implementação desses espaços educativos, voltados para a mudança de conduta dos homens no que tange à forma como se relacionam com as mulheres, poderá favorecer relações mais simétricas entre os gêneros e consequentemente a redução de casos de violência conjugal. Acredita-se que a reflexão, ação e participação masculina constitui uma importante arma para a prevenção e o enfrentamento desse agravo. Além disso, uma limitação do estudo refere-se a não trazer uma abordagem comparativa entre grupos de homens com base na presença ou ausência da experiência de participar dos GR.

\section{Conclusão}

A implementação dos GR enquanto espaços educativos para homens com fins na prevenção de violência conjugal apresenta viabilidade financeira e operacional, mostrando-se de baixo custo, podendo ser replicado por profissionais de diferentes áreas de atuação, em diferentes cenários e com homens de todos os níveis socioculturais. No que tange à enfermagem, esse conhecimento é fundamental para o campo prático, podendo ser implementado pela ESF, nas atividades voltadas para o público masculino, a exemplo do Projeto Sábado do Homem, que ocorre na Atenção Básica de Salvador (BA), ou do Programa Saúde na Escola (PSE) com adolescentes, com foco na prevenção e no enfrentamento da violência.

Tal caminho poderá contribuir para subsidiar o desenvolvimento de GR não apenas no âmbito das varas de violência, conforme preconiza a Lei Maria da Penha, como também replicada no âmbito de empresas, escolas, comunidades, inclusive para homens sem histórico de violência conjugal, sobretudo adolescentes, já que as temáticas de família, gênero, masculinidade e resolução de conflitos de forma pacífica são importantes para o conhecimento de todos os públicos. E ainda para que os homens participem de espaços de reflexão e diálogo, nos quais compartilhem experiências similares, reconhecendo em que grau as suas atitudes podem ser violentas.

\section{Fonte de Financiamento:}

Vinculado ao projeto intitulado "Reeducação de Homens e Mulheres Envolvidos em Processo Criminal: Estratégia de Enfrentamento da Violência Conjugal", financiado pela Fundação de Amparo à Pesquisa do Estado da Bahia (FAPESB).

\section{Colaborações:}

1 - concepção, projeto, análise e interpretação dos dados: Fernanda Matheus Estrela, Nadirlene Pereira Gomes, Andrey Ferreira da Silva, 
Julia Renata Fernandes Magalhães, Anderson Reis de Souza e Álvaro Pereira;

2 - redação do artigo e revisão crítica relevante do conteúdo intelectual: Fernanda Matheus Estrela, Nadirlene Pereira Gomes, Andrey Ferreira da Silva, Julia Renata Fernandes Magalhães, Anderson Reis de Souza e Álvaro Pereira;

3 - aprovação final da versão a ser publicada:

Fernanda Matheus Estrela.

\section{Referências}

1. Evoy CMC, Hideg G. Global violent deaths 2017. Time to Decide. Switzerland: Small Arms Survey; 2017.

2. Carneiro JB, Gomes NP, Estrela FM, Santana JD, Mota RS, Erdmann AL. Domestic violence: repercussions for women and children. Esc Anna Nery. 2017;21(4):e20160346. DOI: http://dx.doi. org/10.1590/2177-9465-ean-2016-0346

3. Szalacha LA, Hughes TL, McNair R, Loxton D. Mental health, sexual identity, and interpersonal violence: Findings from the Australian longitudinal Women's health study. BMC Womens. Health. 2017;17(1):94. DOI: 10.1186/s12905-017-0452-5

4. Marques AM, Velter SC. Gênero e violência: um estudo sobre a Lei Maria da Penha (2006-2011) em Mato Grosso. Hist Cult. 2015;4(3):82-100. DOI: http://dx.doi.org/10.18223/hiscult.v4i3.1693

5. Brasil. Lei n. 11.340, de 7 de agosto de 2006. Cria mecanismos para coibir a violência doméstica e familiar contra a mulher, nos termos do $₫$ o art. 226 da Constituição Federal, da Convenção sobre a Eliminação de Todas as Formas de Discriminação contra as Mulheres e da Convenção Interamericana para Prevenir, Punir e Erradicar a Violência contra a Mulher; dispõe sobre a criação dos Juizados de Violência Doméstica e Familiar contra a Mulher; altera o Código de Processo Penal, o Código Penal e a Lei de Execução Penal; e dá outras providências. Brasília, DF; 2006 [cited 2018 Aug 12]. Available from: http://www.planalto.gov. br/ccivil_03/_ato2004-2006/2006/lei/111340.htm

6. Fleming PJ, Gruskin S, Rojo F, Dworkin SL. Men's violence against women and men are inter-related: Recommendations for simultaneous intervention. Soc Sci Med. 2015;146:249-56. DOI: 10.1016/j. socscimed.2015.10.021

7. Beiras A, Nascimento M. Homens e violência contra mulheres. Pesquisa e intervenções no contexto brasileiro. Rio de Janeiro: Instituto Noos; 2017.

8. Jewkes R, Flood M, Lang J. From work with men and boys to changes of social norms and reduction of inequities in gender relations: a conceptual shift in prevention of violence against women and girls. Lancet. 2015;385(9977):1580-9.

9. Morrison PK, Hawker L, Cluss PA, Miller E, Fleming R, Bicehouse $\mathrm{T}$, et al. The Challenges of Working With Men Who Perpetrate Partner Violence: Perspectives and Observations of Experts Who Work With Batterer Intervention Programs. J Interpers Violence. 2018;1:886260518778258. DOI: $10.1177 / 0886260518778258$

10. Freire P. Pedagogia da autonomia: saberes necessários à prática educativa. São Paulo: Paz e Terra; 2005.

11. Ellsberg M, Arango DJ, Morton M, Gennari F, Kiplesund S, Contreras M, et al. Prevention of violence against women and girls: what does the evidence say? Lancet. 2015 Apr;385(9977):1555-66. DOI: 10.1016/S0140-6736(14)61703-7

12. Razera J, Mosmann CP, Falcke D. The Interface Between Quality and Violence in Marital Relationships. Paidéia. 2016 Apr;26(63):71-9. DOI: http://dx.doi.org/10.1590/1982-43272663201609

13. Beiras A, Nascimento M. Homens e violência contra mulheres. Pesquisa e intervenções no contexto brasileiro. Rio de Janeiro: Instituto Noos; 2017.

14. Lilley-Walker SJ, Hester M, Turner W. Evaluation of European Domestic Violence Perpetrator Programmes: Toward a Model for Designing and Reporting Evaluations Related to Perpetrator Treatment Interventions. Int $\mathrm{J}$ Offender Ther Comp Criminol. 2018 Mar 24;62(4):868-84. DOI: $10.1177 / 0306624 X 16673853$

15. Abramsky T, Devries KM, Michau L, Nakuti J, Musuya T, Kiss L, et al. Ecological pathways to prevention: How does the SASA! community mobilisation model work to prevent physical intimate partner violence against women? BMC Public Health. 2016 Apr 16;16(1):339. DOI: 10.1186/s12889-016-3018-9

16. Moreno CG, Hegarty K, D'Oliveira AFL, McLain JK, Colombini M, Feder G. The health-systems response to violence against women. Lancet. 2015 Apr 18;385(9977):1567-79. DOI: 10.1016/ S0140-6736(14)61837-7 
17. Billand J, Paiva VSF. Desconstruindo expectativas

Recebido: 13 de agosto de 2019 de gênero a partir de uma posição minoritária: como dialogar com homens autores de violência contra mulheres? Ciênc saúde coletiva. 2017 Sep;22(9):2979-88. DOI: http://dx.doi. org/10.1590/1413-81232017229.13742016

Aprovado: 4 de novembro de 2019

Publicado: 4 de dezembro de 2019

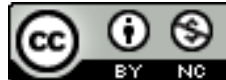

A Revista Baiana de Enfermagem utiliza a Licença Creative Commons - Atribuição-NãoComercial 4.0 Internacional. https://creativecommons.org/licenses/by-nc/4.0/ Este artigo é de acesso aberto distribuído sob os termos da Licença Creative Commons (CC BY-NC). Esta licença permite que outros remixem, adaptem e criem a partir do seu trabalho para fins não comerciais. Embora os novos trabalhos tenham de lhe atribuir o devido crédito e não possam ser usados para fins comerciais, os usuários não têm de licenciar esses trabalhos derivados sob os mesmos termos. 